\title{
Homocysteine levels in men and women of different ethnic and cultural background living in England
}

\author{
Francesco P. Cappuccio ${ }^{\mathrm{a}, *}$, Rachel Bell ${ }^{\mathrm{b}}$, Ivan J. Perry ${ }^{\mathrm{c}}$, Julie Gilg ${ }^{\mathrm{d}}$, Per M. Ueland ${ }^{\mathrm{e}}$, \\ Helga Refsum ${ }^{\mathrm{e}}$, Giuseppe A. Sagnella ${ }^{\mathrm{f}}$, Steve Jeffery ${ }^{\mathrm{b}}$, Derek G. Cook ${ }^{\mathrm{d}}$ \\ a Department of General Practice \& Primary Care, St George's Hospital Medical School, Cranmer Terrace, London SW17 0RE, UK \\ ${ }^{\mathrm{b}}$ Medical Genetics Unit, St George's Hospital Medical School, London, UK \\ ${ }^{\mathrm{c}}$ Department of Epidemiology \& Public Health, University College Cork, Cork, Ireland \\ d Department of Public Health Sciences, St George's Hospital Medical School, London, UK \\ ${ }^{\mathrm{e}}$ Locus for Homocysteine and Related Vitamins, University of Bergen, Bergen, Norway \\ ${ }^{\mathrm{f}}$ Department of Medicine, St George's Hospital Medical School, London, UK
}

Received 5 November 2001; received in revised form 20 December 2001; accepted 28 December 2001

\begin{abstract}
This population-based cross-sectional study in South London looks at the total homocysteine (tHcy) levels in groups of different ethnic background and the possible role of environmental factors and the $677 \mathrm{C} \rightarrow \mathrm{T}$ genetic polymorphism of the methylenetetrahydrofolate reductase (MTHFR). Fasting plasma tHcy was measured in 1392 men and women, age 40-59 years; 475 were white, 465 of African origin (of whom 180 were West Africans and 280 Caribbeans) and 452 South Asian (of whom 222 were Hindus and 167 Muslims). The homozygous MTHFR TT variant had observed frequencies of 0.10 in whites, 0.01 in people of African origin and 0.02 in South Asians $(P<0.001)$. tHcy levels were $16 \%(95 \%$ CI $8-26)$ higher amongst TT than CC. tHcy levels were $25 \%(21-$ 29) higher in men than women. Levels were significantly higher in South Asians than whites (8\% [3-13]). Vegetarians had higher levels than non-vegetarians (25\% [18-33]). These differences were present after adjustments for age, sex, smoking, body mass index $(\mathrm{BMI}), \mathrm{MTHFR}$ 677C $\rightarrow$ T polymorphism and socio-economic status. Compared with whites (10.0 [9.7-10.3] $\mu \mathrm{mol} / \mathrm{l})$, and allowing for confounders, Hindus had significantly higher levels of tHcy $(12.1[11.6-12.6] \mu \mathrm{mol} / \mathrm{l})$. This difference was attenuated by the inclusion of vegetarianism in the model $(11.3$ [10.8-11.9] $\mu \mathrm{mol} / \mathrm{l})$. In contrast Muslims had similar tHcy levels to whites while both West Africans and Caribbeans had slightly lower levels, though differences were not significant. The reported higher levels of tHcy in South Asians are due to high levels amongst Hindus only. They are in part accounted for by their vegetarianism. These differences in tHcy are large enough to be important contributors to the risk of vascular disease and may be preventable by simple targeted population strategies. (C) 2002 Elsevier Science Ireland Ltd. All rights reserved.
\end{abstract}

Keywords: Cardiovascular risk; Coronary Heart Disease; Diet; Ethnicity; Epidemiology; Homocysteine; MTHFR polymorphism; Stroke; Vegetarianism

\section{Introduction}

Cardiovascular disease varies between populations and over time [1]. In the UK, people of African descent have higher stroke morbidity and mortality rates and

\footnotetext{
Abbreviations: CHD, coronary heart disease; tHcy, total homocysteine; MTHFR, methylenetetrahydrofolate reductase.

* Corresponding author. Tel.: +44-20-8725-3329; fax: +44-208725-2234

E-mail address: f.cappuccio@sghms.ac.uk (F.P. Cappuccio).
}

lower rates of coronary heart disease (CHD) than whites. In contrast, people originally from the Indian sub-continent have higher rates of CHD and stroke than whites [1]. These differences are independent of migration [2], suggesting either genetic susceptibility or lifestyle factors that are shared by subgroups of the population and which are retained upon migration.

Smoking, high blood pressure and diabetes are associated with increased risk of disease in South Asians [1]. However, differences in these established risk factors do not fully explain the higher incidence of CHD observed in South Asians and stroke in blacks. 
Elevated circulating levels of total homocysteine (tHcy) are associated with increased risk of CHD, stroke and other occlusive vascular diseases independently from other known risk factors [3-7]. Moreover, tHcy can be reduced by even modest amounts of vitamin B supplementation [8], a very simple and inexpensive treatment of great potential, particularly for elderly people and in developing countries. A common polymorphism (a $\mathrm{C}$ to $\mathrm{T}$ substitution at nucleotide 677 resulting in an alanine-to-valine substitution in the protein) in the methylenetetrahydrofolate reductase (MTHFR) gene has been associated with high levels of tHcy and vascular disease [9]. The presence of the T allele renders the enzyme thermolabile reducing its enzymatic activity and this may cause elevated plasma levels of tHcy [10].

To date, there are few studies that have reported tHcy levels in groups of different ethnic background [11-15]. The study of tHcy in different ethnic groups is of particular importance since stroke is the most important cause of death and disability in populations of African ancestry in the UK and abroad and CHD and stroke are important causes of premature death and morbidity in populations of South Asian origin, particularly in the UK [1].

We examined the tHcy levels in men and women of African descent, South Asian Indian origin and whites co-resident in a geographically defined area of London. We also studied the potential importance of environmental factors and a genetic polymorphism of MTHFR.

\section{Material and methods}

\subsection{Subjects}

The study population is reported in detail elsewhere $[16,17]$. In brief, participants were recruited from the lists of general practices based within the former Wandsworth Health Authority (WHA) in South London. It had a population of approximately 190000 with about $25 \%$ of its residents belonging to ethnic minority groups. From each participating practice, a list was obtained of all men and women aged 40-59 years registered with the practice and resident within the study area. Participants with Chinese, Japanese or Vietnamese names were excluded, as were patients with cancer, severe disability or severe psychiatric disturbance and pregnant women. In order to obtain an approximately equal number of participants in each sex-ethnic specific stratum, all names suggestive of a South Asian origin and of West African origin were selected. In addition, patients of Caribbean origin were identified by a combination of name searching and contact with the general practitioners and the receptionist or practice nurse at the surgery. A random sample of white subjects was then chosen to yield a number of participants approximately equal to the other ethnic groups. Fieldwork was undertaken from March 1994 to July 1996. Ethnic group was recorded at the time of interview based on the answers to a combination of questions including place and country of birth, language, religion, history of migration and parental country of birth $[16,17]$. The response rate was $64 \%$. Within each ethnic group, non-attenders had comparable prevalence of reported hypertension, diabetes, coronary heart disease and stroke [16]. Plasma levels of tHcy were available for 1392 subjects (763 women; 475 white, 465 of African origin, 452 South Asian) and MTHFR polymorphism was measured in 1371 of them (751 women). The study protocol was approved by the Local Ethics Committee. All participants gave their informed consent to participate. South Asians differed by country of birth, language and religion [17]. The commonest religions were Hinduism $(n=221$ or $50 \%)$ and Islam $(n=167$ or $38 \%)$. These differences in religion, unlike differences in language or country of birth, were taken as measures of different diet and lifestyle. Sub-group analysis was, therefore, also performed in these two sub-groups. Amongst people of African origin, the main distinction could be made between those born in the Caribbean $(n=280$ or $60 \%)$ and in West Africa $(n=180$ or $35 \%)$. Sub-group analysis was, therefore, also performed in these two sub-groups.

\subsection{Population methods}

Participants were seen between 08:00 and 12:00 $\mathrm{h}$ after an overnight fast. They were asked to refrain from smoking and from taking vigorous exercise for at least 1 $\mathrm{h}$ before the visit and to bring all medications with them for checking. An administered questionnaire included place and country of birth, language, religion, history of migration, parental place of birth, family and personal medical history and drug therapy. Current and past smoking were recorded as were socio-economic status, current and recent regular use of vitamin supplements and vegetarianism [17]. Height was measured to the nearest $\mathrm{cm}$; weight was measured to the nearest $0.1 \mathrm{~kg}$ with the subject wearing light indoor clothing and no shoes. A standard oral glucose tolerance test was also performed [16,17]. Fasting venous blood was taken in the seated position without stasis as described elsewhere [17].

\subsection{Biochemical and genetic methods}

Plasma tHcy levels were measured by high performance liquid chromatography [18]. Genomic DNA was isolated from whole blood as previously described [1922]. The MTHFR $677 \mathrm{C} \rightarrow \mathrm{T}$ substitution was identified with the use of restriction enzyme digestion of the PCR- 
amplified products, as previously described [23,24]. Genotyping was performed blind and 135 blind duplicates were genotyped as internal controls with $100 \%$ concordance.

\subsection{Statistical analysis}

As tHcy levels were not normally distributed, analyses were carried out on $\log _{\mathrm{e}}$-transformed data. Results are expressed as geometric means $(95 \%$ confidence intervals). The unpaired $t$-test was used to compare means between two groups and analysis of variance (ANOVA) or test for linear trends to compare means of three or more groups. For categorical variables cross-tabulation and chi-square $\left(\chi^{2}\right)$ statistics were used. Multiple regression and analysis of co-variance (ANCOVA) were used to adjust for the effects of confounding variables. Adjusted means are given adjusted to the average value of all other covariates. Hardy-Weinberg equilibrium was tested by $\chi^{2}$ analysis with one degree of freedom.

\section{Results}

\subsection{Characteristics of the population}

The characteristics of the study population are shown in Table 1. The women of African origin had the highest BMI and the men of South Asian origin the lowest. Smoking was most common in white men and was least common in South Asian and African women. The prevalence of hypertension and diabetes was higher amongst ethnic minority groups than whites. In each ethnic group, women were more likely to report vegetarianism [17] and regular use of vitamin supplements $[25,26]$. South Asians had the highest proportion of vegetarians. The vast majority of vegetarians were Hindus (Hindus 105/221 vs. Muslims 3/167).

The MTHFR $\mathrm{T}$ allele frequency was more common amongst whites than the other ethnic groups (Table 2). Homozygosity for the $\mathrm{T}$ allele was rare amongst ethnic minorities so that comparisons have been carried out grouping the CT and TT genotypes. Whilst genotype frequencies did not differ between South Asian Hindus and Muslims (CC: 0.73, CT+TT: 0.27 vs. CC: 0.78 , CT + TT: 0.22 , respectively, $P=0.23$ ), there was a small significant difference between Caribbeans (CC: 0.79, CT+TT: 0.21) and West Africans (CC: 0.87, CT+TT: $0.13 ; P=0.024)$.

\subsection{Fasting plasma tHcy levels}

The frequency distribution of tHcy levels differs markedly from a normal distribution in both men and women. $\log _{e}$ transformation was, therefore, used for the analysis and geometric means are reported. Fasting
tHcy levels were higher in men $(n=629)$ than in women $(n=763)(11.5$ [95\% CI 10.5-12.5] vs. 9.2 [8.2-10.2] $\mu \mathrm{mol} / 1 ; P<0.001)$. Differences between genders were seen across ethnic groups. tHcy levels were significantly higher in South Asians when compared with the other ethnic groups (Table 3). Overall the presence of the T allele was associated with higher tHcy levels in both men and women (Table 3). Finally, tHcy levels were higher in vegetarians than non-vegetarians (Table 3). Differences between sexes were consistent by ethnic group and further analyses were carried out for both sexes combined.

\subsection{Effect of confounding variables}

The effect of confounders was explored in two ways: by adjusting for confounders using multiple regression (Table 4) and by restriction to more homogeneous subgroups (Table 5). To study the variables that may explain the variability in levels of tHcy, three multiple regression models were considered (Table 4). In the first model, allowing for age and sex, and in the second model, allowing also for ethnicity, smoking and BMI, tHcy levels were significantly higher in women and in South Asians. In the third model, vegetarianism and MTHFR polymorphism were added as covariates. In this model the relationships with sex and ethnic group were maintained. High levels of tHcy were also confirmed amongst vegetarians as well as amongst those with the MTHFR $677 \mathrm{C} \rightarrow \mathrm{T}$ genetic variant. Further adjustment for social class did not alter the findings (Percentage difference in tHcy compared with whites was $-2.4 \%[-6.6$ to 1.9$]$ in those of African origin and $7.8 \%$ [3.1-12.7] in South Asians, $P<0.001)$. The differences between ethnic groups remained after excluding current smokers, vegetarians, diabetics, vitamin supplement takers, those with self-reported history of coronary heart disease or stroke (Table 5).

\subsection{Heterogeneity by sub-groups}

tHcy levels were slightly lower in both West African and Caribbeans than whites, though the differences were not statistically significant (Fig. 1). Compared with whites, and allowing for all factors considered in previous models, South Asian Hindus, but not Muslims, had significantly higher levels of tHcy (Fig. 1). However, the majority of vegetarians were amongst the South Asian Hindus (105/140), and the majority of the South Asians were either Hindus or Muslims. Adjustment for vegetarianism explained only part of the difference in tHcy between Hindus and whites, but not all (Fig. 1). The differences between Muslims and Hindus remained after excluding current smokers, vegetarians, diabetics, vitamin supplement takers, those with self-reported history of coronary heart disease or stroke (Table 5). 
Table 1

Characteristics of men and women aged 40-59 years of different ethnic groups living in Wandsworth, South London, 1994-1996

\begin{tabular}{|c|c|c|c|c|}
\hline Men & White $(n=214)$ & African origin $(n=182)$ & South Asian $(n=233)$ & $P$ \\
\hline Age (years) & $50.5(5.7)$ & $52.1(5.7)$ & $49.4(5.9)$ & $<0.001$ \\
\hline $\operatorname{BMI}\left(\mathrm{kg} / \mathrm{m}^{2}\right)^{\mathrm{a}}$ & $26.0(4.2)$ & $26.6(3.8)$ & $24.7(3.6)$ & $<0.001$ \\
\hline Waist:hip ratio ${ }^{a}$ & $0.925(0.061)$ & $0.923(0.059)$ & $0.940(0.060)$ & 0.004 \\
\hline Smoking $^{\mathrm{a}}$ & & & & 0.001 \\
\hline Current & $39.4(84)$ & $19.8(36)$ & $25.3(59)$ & \\
\hline Ex & $39.4(84)$ & $28.0(51)$ & $19.3(45)$ & \\
\hline Never & $21.1(45)$ & $52.2(95)$ & $55.4(129)$ & \\
\hline Social class ${ }^{\mathrm{b}}$ & & & & $<0.001$ \\
\hline $\mathrm{I}+\mathrm{II}$ & $40.8(87)$ & $18.8(34)$ & $45.0(103)$ & \\
\hline $\mathrm{IIINM}+\mathrm{M}$ & $46.0(98)$ & $48.6(88)$ & $45.0(103)$ & \\
\hline $\mathrm{IV}+\mathrm{V}$ & $13.1(28)$ & $32.6(59)$ & $10.0(23)$ & \\
\hline Hypertension & $18.2(39)$ & $41.2(75)$ & $28.3(66)$ & 0.001 \\
\hline Diabetes $^{c}$ & $5.1(9)$ & $19.1(28)$ & $23.8(48)$ & 0.001 \\
\hline Self-reported CHD or stroke ${ }^{d}$ & $7.5(16)$ & $7.7(14)$ & $8.2(19)$ & 0.956 \\
\hline Vegetarians & $1.9(4)$ & $1.1(2)$ & $17.2(40)$ & 0.001 \\
\hline Vitamin supplement takers & $6.1(13)$ & $4.4(8)$ & $2.6(6)$ & 0.189 \\
\hline Women & White $(n=261)$ & African origin $(n=283)$ & South Asian $(n=219)$ & $P$ \\
\hline Age (years) & $49.3(5.7)$ & $50.6(5.8)$ & $48.9(5.7)$ & 0.002 \\
\hline BMI $\left(\mathrm{kg} / \mathrm{m}^{2}\right)^{\mathrm{e}}$ & $25.8(4.8)$ & $29.3(4.6)$ & $27.1(4.7)$ & $<0.001$ \\
\hline Waist:hip ratio ${ }^{\mathrm{f}}$ & $0.798(0.071)$ & $0.832(0.086)$ & $0.845(0.086)$ & $<0.001$ \\
\hline Smoking $\mathrm{g}$ & & & & 0.001 \\
\hline Current & $33.3(87)$ & $7.8(22)$ & $3.2(7)$ & \\
\hline Ex & $28.4(74)$ & $8.8(25)$ & $1.8(4)$ & \\
\hline Never & $38.3(100)$ & $83.4(236)$ & $95.0(208)$ & \\
\hline Social class ${ }^{\mathrm{h}}$ & & & & $<0.001$ \\
\hline $\mathrm{I}+\mathrm{II}$ & $36.0(90)$ & $26.4(70)$ & $45.4(89)$ & \\
\hline IIINM+M & $45.6(114)$ & $46.4(123)$ & $39.3(77)$ & \\
\hline $\mathrm{IV}+\mathrm{V}$ & $18.4(46)$ & $27.2(72)$ & $15.3(30)$ & \\
\hline Hypertension & $12.6(33)$ & $42.1(119)$ & $23.3(51)$ & 0.001 \\
\hline Diabetes $^{\mathrm{i}}$ & $4.9(10)$ & $14.2(33)$ & $18.1(33)$ & 0.001 \\
\hline Self-reported CHD or stroke $\mathrm{j}^{\mathrm{j}}$ & $8.8(23)$ & $12.8(36)$ & $7.4(16)$ & 0.101 \\
\hline Vegetarians $\mathrm{s}^{\mathrm{k}}$ & $5.8(15)$ & $0.7(2)$ & $35.3(77)$ & 0.001 \\
\hline Vitamin supplement takers & $10.0(26)$ & $11.0(31)$ & $9.6(21)$ & 0.869 \\
\hline
\end{tabular}

Results are means (S.D.) and percentages $(n) . P$ values are for test of heterogeneity between ethnic groups by ANOVA or $\chi^{2}$ statistics.

a 213 whites, 182 African origin and 233 South Asians.

b 213 whites, 181 African origin and 229 South Asians.

c 177 whites, 147 African origin and 202 South Asians.

d 214 whites, 181 African origin and 231 South Asians.

e 261 whites, 281 African origin and 218 South Asians.

f 261 whites, 282 African origin and 219 South Asians.

g 261 whites, 283 African origin and 219 South Asians.

h 250 whites, 265 African origin and 196 South Asians.

i 206 whites, 233 African origin and 182 South Asians.

j 261 whites, 281 African origin and 217 South Asians.

k 260 whites, 283 African origin and 218 South Asians.

\section{Discussion}

\subsection{Main findings}

The results of this population-based study of multiethnic middle-aged men and women indicate that there are important differences in fasting tHcy levels between genders and ethnic groups. These differences are independent of a number of confounding factors including the MTHFR $677 \mathrm{C} \rightarrow \mathrm{T}$ genetic variant. Whilst the study confirms that South Asians have higher levels of tHcy, it clearly indicates that these differences are confined to those of Hindu religion only. Furthermore, the high levels of tHcy in Hindus were in part, but not entirely, explained by the dietary habit of vegetarianism, suggesting additional effects of other exposures not directly measured in the present study.

There have been few studies of tHcy and ethnicity. Ubbink et al. [11] studied young black normal volunteers in South Africa in fasting conditions and after a methionine load. Fasting tHcy concentrations were lower in blacks than in whites, suggesting that African 
Table 2

MTHFR genotype frequency (\%) by gender and ethnic group

\begin{tabular}{lrrrr}
\hline & \multicolumn{2}{l}{ MTHFR Genotype } & \multirow{2}{*}{$P$} \\
\cline { 2 - 4 } & CC N (\%) & CT $N(\%)$ & TT $N(\%)$ & \\
\hline Men $(n=620)$ & $101(48.1)$ & $91(43.3)$ & $18(8.6)$ & $<0.001$ \\
White & $140(77.8)$ & $37(20.5)$ & $3(1.7)$ & \\
African origin & $169(73.5)$ & $57(24.8)$ & $4(1.7)$ & \\
South Asian & & & & $<0.001$ \\
Women $(n=751)$ & $108(42.2)$ & $117(45.7)$ & $31(12.1)$ & \\
White & $234(84.2)$ & $41(14.7)$ & $3(1.1)$ & \\
African origin & $164(75.6)$ & $48(22.1)$ & $5(2.3)$ & \\
South Asian & &
\end{tabular}

$\mathrm{P}$ values are by $\chi^{2}$ analysis for heterogeneity between ethnic groups.

blacks may be protected from CHD because of the lower levels of tHcy. The intriguing and paradoxical result of a blunted tHcy response in an ethnic group at a greater risk of stroke either suggests that important interactions with other risk factors may be taking place in modifying the vascular effects of homocysteine, or that tHcy is not causally related to vascular disease.

UK Indian Asian men with evidence of CHD have higher levels of tHcy than European men with CHD [12]. However, the results only apply to men, the heterogeneity between South Asian subgroups was not taken into account [27] and the study did not allow for the possibility of increased tHcy after the coronary event $[28,29]$. The same study also indicates that the presence of the MTHFR T mutation does not contribute to the raised levels of tHcy in South Asians with CHD [15], although there was no attempt to look at differences between Hindus, Muslims and Sikhs. The SHARE study showed higher levels of fasting tHcy amongst Canadians of South Asian ancestry [13]. However, given the heterogeneity of the South Asian populations in that study (34\% Hindus, 27\% Muslims and 25\% Sikhs) and their different cardiovascular risk profile [27], it is not clear whether all subgroups had similarly raised levels. Our study adds to the current knowledge in that it suggests that South Asian Hindus, but not Muslim, have raised levels of tHcy.

Stroke mortality also varies by ethnic group [1]. Strokes are more often atherothrombotic amongst South Asians whilst hypertensive lesions and small vessel disease are more likely causes of stroke in blacks. High levels of tHcy in South Asian Hindus, but not in people of African origin, may be consistent with these different mechanisms.

\subsection{Strengths and limitations}

Our study is population-based and used random sampling from the general population co-resident in an inner city borough with a high proportion of ethnic minority populations. The participants lived within the same geographical area and this might have mitigated some potential effects of differences in environmental background. The study examined first generation immigrants of ethnic minority groups with both parents born in the country of origin and belonging to the same ethnic background, thus markedly reducing the possible impact arising from an unknown degree of admixture. We used standardised methods across all ethnic groups, thus minimising systematic bias. In our study, high levels of tHcy in South Asians were detected in those without symptomatic CHD and in women, excluding gender differences by ethnicity. More importantly, our study shows that assumptions on ethnic group definition

Table 3

Age-adjusted tHcy levels by gender, ethnic groups, MTHFR genotype and vegetarianism

\begin{tabular}{|c|c|c|c|c|}
\hline & \multicolumn{2}{|c|}{ Men $(n=629)$} & \multicolumn{2}{|c|}{ Women $(n=763)$} \\
\hline & $n$ & Geometric mean $(95 \% \mathrm{CI})$ & $n$ & Geometric mean $(95 \% \mathrm{CI})$ \\
\hline \multicolumn{5}{|l|}{ Ethnic group } \\
\hline White & 214 & $10.8(10.4-11.2)$ & 261 & $9.3(9.0-9.7)$ \\
\hline African origin & 182 & $11.0(10.6-11.5)$ & 283 & $8.4(8.1-8.7)$ \\
\hline South Asian & 233 & $12.5(12.1-13.0)$ & 219 & $10.0(9.6-10.4)$ \\
\hline$P$ value & & $<0.001$ & & $<0.001$ \\
\hline \multicolumn{5}{|c|}{ MTHFR genotype } \\
\hline $\mathrm{CC}$ & 410 & $11.3(11.0-11.6)$ & 506 & $9.0(8.7-9.4)$ \\
\hline $\mathrm{CT}$ & 185 & $11.6(11.1-12.0)$ & 206 & $9.4(9.0-9.8)$ \\
\hline TT & 25 & $13.2(11.8-14.7)$ & 39 & $10.3(9.4-11.4)$ \\
\hline$P$ value & & 0.025 & & 0.01 \\
\hline \multicolumn{5}{|l|}{ Vegetarianism } \\
\hline No & 583 & $11.2(11.0-11.5)$ & 669 & $8.9(8.7-9.1)$ \\
\hline Yes & 46 & $15.1(14.0-16.4)$ & 92 & $11.5(10.8-12.3)$ \\
\hline$P$ value & & $<0.001$ & & $<0.001$ \\
\hline
\end{tabular}

$P$ values are for test of heterogeneity between ethnic groups by ANCOVA. 
Table 4

Percentage effect on fasting plasma levels of tHcy of selected variables after adjustment for confounding variables

\begin{tabular}{|c|c|c|c|c|c|c|c|c|c|}
\hline & \multicolumn{3}{|c|}{ Model $1^{\mathrm{a}}$} & \multicolumn{3}{|c|}{ Model $2^{\mathrm{b}}$} & \multicolumn{3}{|c|}{ Model $3^{\mathrm{c}}$} \\
\hline & $n$ & & $P$ & $n$ & & $P$ & $n$ & & $P$ \\
\hline Age ( $\%$ per10 years) & 1392 & $7.0(3.7,9.6)^{*}$ & $<0.001$ & 1381 & $8.5(5.6,11.6)$ & $<0.001$ & 1354 & $7.5(4.7,10.5)$ & $<0.001$ \\
\hline BMI $\left(\%\right.$ per $\left.\mathrm{kg} / \mathrm{m}^{2}\right)$ & 1388 & $-0.1(-0.5,2.0)$ & 0.57 & 1381 & $0.2(-0.2,0.5)$ & 0.37 & 1354 & $0.3(-0.1,0.7)$ & 0.07 \\
\hline Sex & & & $<0.001$ & & & $<0.001$ & & & $<0.001$ \\
\hline Females & 763 & 0 & & 760 & 0 & & 746 & 0 & \\
\hline Males & 629 & $24.5(20.6,28.6) \#$ & & 627 & $23.4(19.2,27.6)$ & & 618 & $25.1(21.0,29.4)$ & \\
\hline Ethnic groups & & & $<0.001$ & & & $<0.001$ & & & $<0.001$ \\
\hline White & 475 & 0 & & 473 & 0 & & 463 & 0 & \\
\hline African origin & 465 & $-5.2(-8.8,-1.4)$ & & 463 & $-5.5(-9.4,-1.5)$ & & 456 & $-2.1(-6.2,2.1)$ & \\
\hline South Asian & 452 & $11.0(6.7,15.2)$ & & 457 & $10.6(6.1,15.4)$ & & 445 & $7.9(3.3,12.7)$ & \\
\hline Smoking & & & 0.008 & & & 0.023 & & & 0.025 \\
\hline Never & 813 & 0 & & 809 & 0 & & 798 & 0 & \\
\hline Ex & 283 & $-5.6(-9.5,-1.5)$ & & 283 & $-3.7(-7.9,7.6)$ & & 276 & $-2.8(-6.9,1.6)$ & \\
\hline Current & 295 & $1.6(-2.5,6.0)$ & & 295 & $3.2(-1.1,7.8)$ & & 290 & $3.9(-0.5,8.4)$ & \\
\hline MTHFR polymorphism & & & & & & & & & $<0.001$ \\
\hline $\mathrm{CC}$ & & & & & & & 910 & 0 & \\
\hline $\mathrm{CT}$ & & & & & & & 390 & $4.8(1.1,8.6)$ & \\
\hline $\mathrm{TT}$ & & - & & & - & & 64 & $16.4(7.9,25.6)$ & \\
\hline Vegetarians & & & & & & & & & $<0.001$ \\
\hline No & & & & & & & 1231 & 0 & \\
\hline Yes & & - & & & - & & 133 & $25.2(18.4,32.6)$ & \\
\hline
\end{tabular}

${ }^{a}$ Model 1 adjusts for age and sex as covariates; *sex-adjusted; \#age-adjusted.

b Model 2 includes Model 1 plus ethnicity, smoking and BMI as covariates.

c Model 3 includes Model 2 plus vegetarianism and MTHFR polymorphism as covariates.

Results are expressed as percentage change from reference group or per unit change of dependent variable $(95 \% \mathrm{CI})$.

should be carefully considered in the light of the hypothesis being tested. As far as tHcy levels are concerned, there was a clear effect in a subgroup of South Asians. The vegetarian Hindus had the highest levels of tHcy compared with South Asian non-vegetarian Muslims.

There are limitations to our study. We did not measure vitamin $B_{12}$ and folate. However, higher levels of tHcy in South Asians are explained by reduced concentrations of vitamin $B_{12}$ and folate [12]. Reduced intake of vitamin $B_{12}$ and signs of cobalamine deficiency have indeed been reported in South Asian populations $[30,31]$. Prolonged cooking of vegetables may destroy up to $90 \%$ of folate content $[30,32,33]$. This is common practice amongst vegetarian Hindus and it is consistent with the high levels of tHcy we detected, and with the previously reported low levels of plasma vitamin C amongst South Asians [25]. A similar justification may also explain the rather lower levels of tHcy amongst blacks, whose diet may contain more fruit and raw vegetables [34].

Our study indicates that South Asian Hindus have higher levels of tHcy than other ethnic groups, in part (though not exclusively) due to their vegetarianism. In contrast, people of African origin tend to have lower levels of tHcy than whites.

Table 5

Adjusted* geometric means levels of tHcy after exclusions

\begin{tabular}{|c|c|c|c|c|c|c|c|}
\hline & \multirow[t]{2}{*}{$n$} & \multirow[t]{2}{*}{ White } & \multirow[t]{2}{*}{ African origin } & \multirow[t]{2}{*}{ South Asian } & \multicolumn{3}{|c|}{ South Asian } \\
\hline & & & & & $n$ & Muslim & Hindu \\
\hline All & 1376 & 10.0 & 9.5 & 11.1 & 1314 & 10.1 & 12.1 \\
\hline \multicolumn{8}{|l|}{ Excluding } \\
\hline Current smokers & 1085 & 9.8 & 9.4 & 10.9 & 1036 & 9.9 & 12.0 \\
\hline Vegetarians & 1236 & 10.0 & 9.5 & 10.3 & 1183 & 10.1 & 10.7 \\
\hline Diabetics & 1215 & 10.0 & 9.6 & 11.0 & 1162 & 10.0 & 11.9 \\
\hline Self-reported CHD or stroke & 1253 & 10.0 & 9.4 & 11.2 & 1194 & 10.1 & 12.2 \\
\hline
\end{tabular}

*Adjusted for age, sex and BMI. For each row of the table $P<0.001$ for differences between ethnic groups. Values have been log transformed for the analyses and then transformed back for presentation here. 


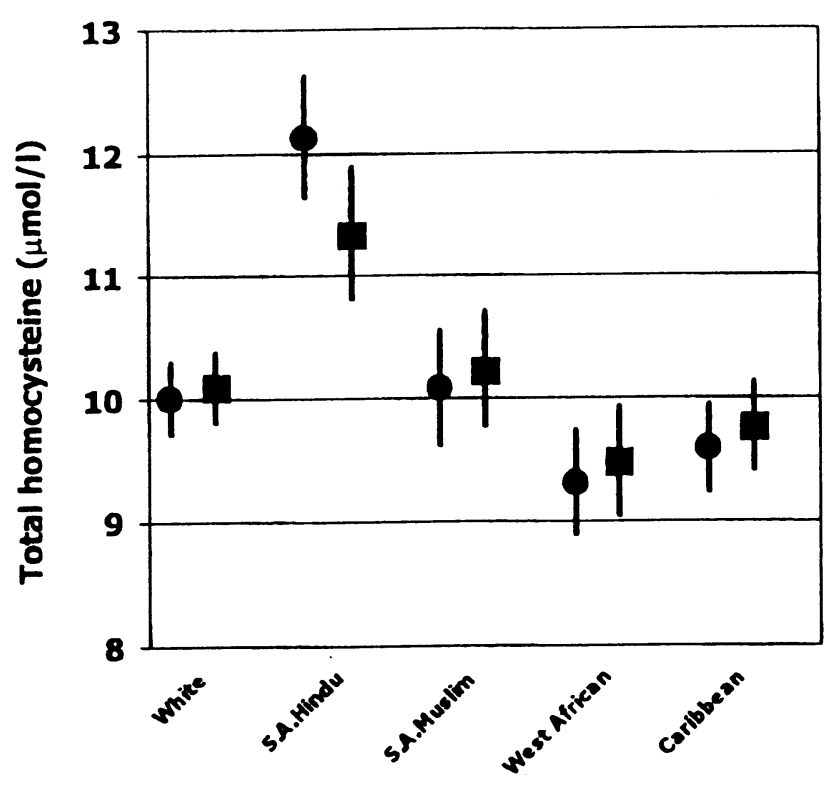

Fig. 1. Plasma fasting tHcy levels (geometric mean and $95 \%$ CI) in people from different ethnic sub-groups, after adjustment for age, sex, BMI and smoking (model 1 as circles) and after further adjustment for vegetarianism (model 2 as squares). $P<0.001$ by ANCOVA.

\section{Acknowledgements}

We wish to thank the General Practitioners in Wandsworth for allowing us to approach people on their lists, the staff of the Blood Pressure Unit and the Department of Public Health Sciences for their support. We also thank the people of Wandsworth who took part in the study. A list of the Wandsworth Heart \& Stroke Study Group is given elsewhere [17]. Francesco P. Cappuccio, Derek G. Cook, Giuseppe A. Sagnella and Steve Jeffery are members of the St. George's Cardiovascular Research Group. The study was supported by The Stroke Association (Project Grant No. 23/97) and by grants from the former Wandsworth Health Authority, South Thames Regional Health Authority, NHS R\&D Directorate, British Heart Foundation, British Diabetic Association and the EU Commission Demonstration Project Contract BMH4-CT98-3549.

\section{References}

[1] Cappuccio FP. Ethnicity and cardiovascular risk: variations in people of African ancestry and South Asian origin. J Hum Hypert 1997;11:571-6.

[2] McKeigue PM, Miller GJ, Marmot MG. Coronary heart disease in South Asians overseas: a review. J Clin Epidemiol 1989;42:597-609.

[3] Refsum H, Ueland PM, Nygard O, Vollset SE. Homocysteine and cardiovascular disease. Ann Rev Med 1998;49:31-62.

[4] Eikelboom JW, Lonn E, Genest J, Jr, Hankey G, Yusuf S. Homocyst(e)ine and cardiovascular disease: a critical review of the epidemiological evidence. Ann Intern Med 1999;131:363-75.
[5] Ueland PM, Refsum H, Beresford SA, Vollset SE. The controversy over homocysteine and cardiovascular risk. Am J Clin Nutr 2000;72:324-32.

[6] Christen WG, Ajani UA, Glynn RJ, Hennekens CH. Blood levels of homocysteine and increased risks of cardiovascular disease. Causal or casual? Arch Intern Med 2000;160:422-34.

[7] Whincup PH, Refsum H, Perry IJ, et al. Serum total homocysteine and coronary heart disease: prospective study in middle aged men. Heart 1999;82:448-54.

[8] Homocysteine Lowering Trialists' Collaboration. Lowering blood homocysteine with folic acid based supplements: meta-analysis of randomised trials. Br Med J 1998;316:894-8.

[9] Moghadasian MH, McManus BM, Frohlich JJ. Homocyst(e)ine and coronary heart disease. Clinical evidence and genetic and metabolic background. Arch Intern Med 1997;157:2299-308.

[10] Jacques PF, Bostom AG, Williams RR, et al. Relation between folate status, a common mutation in methylenetetrahydrofolate reductase and plasma homocysteine concentrations. Circulation 1996;93:7-9.

[11] Ubbink JB, Vermaak WJH, Delport R, van der Merwe A, Becker PJ, Potgieter H. Effective homocysteine metabolism may protect South African blacks against coronary heart disease. Am J Clin Nutr 1995;62:802-8.

[12] Chambers JC, Obeid OA, Refsum H, et al. Plasma homocysteine concentrations and risk of coronary heart disease in UK Indian Asian and European men. Lancet 2000;355:523-7.

[13] Anand SS, Yusuf S, Vuksan V, et al. Differences in risk factors, atherosclerosis, and cardiovascular disease between ethnic groups in Canada: the Study of Health Assessment and Risk in Ethnic groups (SHARE). Lancet 2000;356:279-84.

[14] Hankey GJ, Eikelboom JW. Homocysteine and vascular disease. Lancet 1999;354:407-13.

[15] Chambers JC, Ireland H, Thompson E, et al. Methylenetetrahydrofolate reductase $677 \mathrm{C}-\mathrm{T}$ mutation and coronary heart disease risk in UK Indian Asians. Arterioscler Thromb Vasc Biol 2000;20:2448-52.

[16] Cappuccio FP, Cook DG, Atkinson RW, Strazzullo P. Prevalence, detection, and management of cardiovascular risk factors in different ethnic groups in south London. Heart 1997;78:555-63.

[17] Cappuccio FP, Cook DG, Atkinson RW, Wicks PD. The Wandsworth Heart and Stroke Study. A population-based survey of cardiovascular risk factors in different ethnic groups. Methods and baseline findings. Nutr Metab Cardiovasc Dis 1998;8:371-85.

[18] Fiskerstrand T, Refsum H, Kvalheim G, Ueland PM. Homocysteine and other thiols in plasma and urine: automated determination and sample stability. Clin Chem 1993;39:263-71.

[19] Sagnella GA, Rothwell MJ, Onipinla AK, Wicks PD, Cook DG, Cappuccio FP. A population study of ethnic variations in the angiotensin-converting enzyme I/D polymorphism: relationships with gender, hypertension and impaired glucose metabolism. J Hypertens 1999;17:657-64.

[20] Hall S, Talmud PJ, Cook DG, et al. Frequency and allelic association of common variants in the lipoprotein lipase gene in different ethnic groups. The Wandsworth Heart \& Stroke Study. Gen Epidemiol 2000;18:203-16.

[21] Dong YB, Zhu HD, Sagnella GA, Carter ND, Cook DG, Cappuccio FP. Association between the C825T polymorphism of the $\mathrm{G}$ protein $\beta 3$-subunit gene and hypertension in blacks. Hypertension 1999;34:1193-6.

[22] Waterworth DM, Talmud PJ, Humphries SE, et al. Variable effects of the ApoCIII $-482 \mathrm{C}>\mathrm{T}$ variant on insulin, glucose and triglyceride levels in different ethnic groups. The Wandsworth Heart \& Stroke Study. Diabetologia 2001;44:245-8.

[23] Frosst P, Blom HJ, Milos R, et al. A candidate genetic risk factor for vascular disease: a common mutation in methylenetetrahydrofolate reductase. Nat Genet 1996;10:111-3. 
[24] Malik NM, Syrris P, Schwartzman R, et al. The methylenetetrahydrofolate reductase polymorphism $(\mathrm{C}-677 \mathrm{~T})$ and coronary heart disease. Clin Sci 1998;95:311-5.

[25] Ness AR, Cappuccio FP, Atkinson RW, Khaw K-T, Cook DG. Plasma vitamin $\mathrm{C}$ levels in men and women from different ethnic backgrounds living in England. Int J Epidemiol 1999;28:450-5.

[26] Cappuccio FP, Duneclift SM, Atkinson RW, Cook DG. Use of alternative medicines in a multi-ethnic population. Ethnicity Dis 2001;11:11-8.

[27] Bhopal R, Unwin N, Alberti KGMM, et al. Heterogeneity of coronary heart disease risk factors in Indian, Pakistani, Bangladeshi, and European origin populations: cross sectional study. $\mathrm{Br}$ Med J 1999;319:215-20.

[28] Egerton W, Silberberg J, Crooks R, Ray C, Xie L, Dudman N. Serial measures of plasma homocyst(e)ine after acute myocardial infarction. Am J Cardiol 1996;77:759-61.
[29] Dudman NPB. An alternative view of homocysteine. Lancet 1999;354:2072-4.

[30] Dawson DW, Waters HM. Malnutrition: folate and cobalamin deficiency. Br J Biomed Sci 1994;51:221-7.

[31] Refsum H, Yajnik CS, Gadkari M, et al. Hyperhomocysteinemia and elevated methylmalonic acid indicate a high prevalence of cobalamine deficiency in Asian Indians. Am $\mathbf{J}$ Clin Nutr 2001;74:233-41.

[32] Abraham R, Brown MC, North WR, McFadyen IR. Diets of Asian pregnant women in Harrow: iron and vitamins. Hum Nutr Appl Nutr 1987;41:164-73.

[33] Matthews JH, Wood JK. Megaloblastic anaemia in vegetarian Asians. Clin Lab Haematol 1984;6:1-7.

[34] Sharma S, Cade J, Griffiths S, Cruickshank K. Nutrient intakes among UK African-Caribbeans: changing risk of coronary heart disease. Lancet 1998;352:114-5. 